http://economix.fr

\title{
Introducing global term structure in a risk parity framework
}

Document de Travail

Lauren Stagnol

\section{Working Paper} 2017-23 


\title{
Introducing global term structure in a risk parity framework
}

\author{
Lauren Stagnol*
}

April 21, 2017

\begin{abstract}
In this paper, we aim at constructing a global risk model using the term structure from major bond-issuing countries. The goal is twofold: first this allows quantifying global interest rate risk (level, slope and curvature effects), providing insights on global risks at play. Secondly, such information could be used in order to design sovereign bond indexes in a risk parity framework where each country's sensitivity to global interest risk is accounted for. More specifically, we propose two innovative indexing schemes, a first one where we equalize contribution to global level risk exposures across countries, and a second one where we turn to level, slope and curvature risk exposures within a country. Indeed at the country level, only parallel (level) risk matters, while when turning to maturity buckets within a country, non parallel risks (slope and curvature) have to be accounted for. Finally, we demonstrate that the conjunctive use of these two approaches allows to efficiently tackle exposure to global interest rate risk while providing appealing improvements in the risk-return profile.
\end{abstract}

JEL Classification: G10, G11, G15

Keywords: Equal Risk Contribution, Yield Curve, Risk Parity, Smart Beta, Risk Measure, Risk-Based Indexing, Sovereign Bonds, Term Structure

\section{Introduction}

At the end of 2016, where the spread between US and European government bond yields reaches unprecedented level ${ }^{1}$ being able to understand and quan-

*EconomiX-CNRS, University of Paris Ouest Nanterre La Défense, 200 avenue de la République, 92000 Nanterre, France and Amundi Asset Management, 91 boulevard Pasteur, 75015 Paris, France. Email: l.stagnol@gmail.com. Tel: +33 (0)1 409777 93. The views expressed in this paper are those of the author and do not necessarily reflect those of Amundi. I am very grateful to Marielle de Jong and Thierry Roncalli for helpful comments and suggestions.

${ }^{1}$ The spread between the US (USGG10YR Index) and German (GDBR10 Index) 10 Years Government bond yields reached 235 bps, according to Bloomberg data. 
tify the common trends among major countries' term structure appears to be of prime concern for both practitioners and policy makers. A quick look to stylized facts from country's yields allows to perceive the existence of patterns that appear to be of global scale. If the literature is rich on the modeling of a country's yield curve, fewer studies exist concerning the specification of a global term structure. This paper tries to answer the following questions : is there a case for a global yield curve? How it can be used in the design of a risk parity sovereign bonds index?

The question on how to model the yield across different maturities for a single country has largely been addressed and models have been competing for a while now. More technically, such exercise implies extracting zero coupon prices from current coupon bond prices. However in practice zero coupon bonds are not common on the marketplace, therefore indirect methods have to be employed in order to obtain zero coupon bond prices. The main idea is to build a function using parameters that are specific to a maturity length. Parameters are then estimated so that the fit is maximized across the whole term structure. Polynomial and exponential splines that aim at modeling the discount function are the most commonly used (McCulloch, 1971, 1975; Vasicek, 1977; Vasicek and Fong, 1982). Despite effectiveness, one of the drawbacks of these methods is that parameters may lack of economic interpretation. In addition, the number of splines to use is still debated.

Consequently, other methods have been developed, that switch from estimating discount function towards fitting the zero-coupon yield curve. One of the most commonly used methods is the Nelson Siegel model (Nelson and Siegel, 1987). One of this method's advantages is the parsimony in its parametrization, namely three coefficients that have an economic meaning, plus an adjustment parameter lambda (Martellini and Priaulet, 2000). In addition it allows obtaining the most common shapes for the term structure (as opposed to Cox et al. (1985) for instance). Some models subsequently developed (Svensson, 1994; Björk and Christensen, 1999) allow even more realistic yield curves with potential bumps, however for a matter of parsimony and relatedness to economic metrics, we prefer the Nelson Siegel approach as in Diebold et al. (2008). An interesting extension of Nelson Siegel model is the dynamic version presented by Diebold and $\operatorname{Li}$ (2006), where the three structural parameters are time-dependent.

As mentioned by Diebold et al. (2008), despite tremendous interest for bonds yields drivers, their determinants at the global scale is not yet fully explored in the literature. As a matter of fact, if cross-country linkages have been considered (Campbell and Clarida, 1987), there is still a gap in the understanding of a common global term structure affecting bonds yields at the country level. This raises two related questions: how much a country contributes to a "world term structure" and, in turn, how sensitive is this region to such global fluctuations? A few papers turned towards this question. Dungey et al. (2000) employed a factor analysis to decompose 10 year bonds spreads of major countries com- 
pared to US. However, by choosing such reference point they implicitly discard US from their estimation of a "world rate". Indeed, Dahlquist and Hasseltoft (2013) modeled an international bond risk premia and found that it is closely linked to US economy. The paper the closest to our work is Diebold et al. (2008) where the authors present an empirical application of a dynamic version of Nelson Siegel introduced in a companion paper (Diebold and Li, 2006), on a panel of four countries (United States, United Kingdom, Japan and Germany) where they estimate global level and slope factors. Using a less restrictive model, Bai and Wang (2012) corroborate the importance of such global factors in explaining country yields. It seems that there is consensus on the existence of global level, slope and curvature factors ${ }^{2}$. However, the drivers of these factors are still debated. For the level factor, literature tends to agree on its link to global inflation, while real activity / economic growth seems to drive the slope factor (Diebold and Li, 2006; Diebold et al., 2008; Abbritti et al., 2013). Debates remain concerning curvature, but Abbritti et al. (2013) suggest it might be a predictor of future economic and financial instability.

In this paper, we raise the following question: how can global term structure factors modeling help designing a sovereign bonds index? More specifically our objective is twofold: we are keen to model global term structure and to incorporate it in the design of a risk parity sovereign bond index. In order to do so, state-space modeling is employed and the indexes proposed are backtested on the strictest definition of the risk party framework: the Equal Risk Contribution scheme (ERC hereafter). By doing so, we contribute to the literature in several points. First, we introduce the use of the global yield curve within an index design. Second, considering our sample of developed countries we turn towards interest rate risk in an ERC framework, rather than credit risk. This is something we have not seen yet in the literature. Last but not least, we propose an innovative metric for appraising bond risk: its exposure to global term structure movements. We show that applying an equal global interest rate risk contribution scheme between and within a country allows substantial improvements in the risk return framework.

This paper is organized as follows: section 2 is devoted to the presentation of the model used in order to capture global trends in the term structure. Results are presented in section 3. In section 4 we incorporate this global risk factor in the design of a sovereign bond index in a risk parity framework proposing two strategies: one that aims at equalizing global parallel risk across countries and one that manage both parallel and non parallel shifts within a country. Section 5 concludes this paper.

\footnotetext{
${ }^{2}$ Interested readers can turn to Rudebusch (2010) for a thorough survey.
} 


\section{Methodology}

\subsection{Modeling the term structure at the country level}

First, and in order to better motivate the relevance of level, slope and curvature factors as determinants of yields, we present below in Table 1 the Principal Component Analysis (PCA) results obtained from monthly yields variations ${ }^{3}$ of different maturities (1, 3, 5, 7, 10, 15 and 20 years) between 01/31/1997 and 08/31/2016 from the BofA Merrill Lynch Government Index (W0G1) for nine major bond issuers, in the spirit of Litterman and Scheinkman (1991). We choose to work on G7 countries, augmented with Sweden and Australia, to grasp a European country whom money is not the Euro and the Oceania region. These three factors alone allow explaining almost all the variance in yields, a

Table 1: PCA Results

\begin{tabular}{lccc}
\hline Proportion of variance explained & Level & Slope & Curvature \\
\hline Australia & $91 \%$ & $8 \%$ & $1 \%$ \\
Canada & $87 \%$ & $11 \%$ & $2 \%$ \\
Germany & $84 \%$ & $13 \%$ & $2 \%$ \\
France & $84 \%$ & $13 \%$ & $2 \%$ \\
United Kingdom & $84 \%$ & $12 \%$ & $3 \%$ \\
Italy & $88 \%$ & $9 \%$ & $3 \%$ \\
Japan & $84 \%$ & $12 \%$ & $3 \%$ \\
Sweden & $81 \%$ & $14 \%$ & $4 \%$ \\
United States & $88 \%$ & $10 \%$ & $2 \%$ \\
\hline
\end{tabular}

Source: Authors' calculations based on data extracted from BofA ML.

result in line with the literature (Litterman and Scheinkman, 1991). On average, the level factor accounts for most of the variability, with $86 \%$, followed by the slope factor with $11 \%$, while the curvature factor has less explanatory power for yields movements. Therefore, it makes sense to appraise sovereign bond risk with interest rate metrics.

In this section, we are keen to estimate global level, slope and curvature factors. In order to do so, we have to proceed as follows. First we have to collect market data (yield) at the country level for different maturities and potentially deal with missing data. Second, using the latter in a Dynamic Nelson Siegel (DNS) framework allows us to extract each country term structure, parsimoniously summed up with the three factors (level, slope and curvature). These factors are then introduced as an input in a state-space modeling framework and using Kalman filtering, we estimate a global level and slope factors following Diebold et al. (2008), as well as a curvature factor.

\footnotetext{
${ }^{3}$ Indeed Lardic et al. (2003) recommend to work on change in yield data rather than on their levels, since the latter are much more correlated and typically not stationary.
} 
We collect monthly snapshots from the W0G1 index provided by Merrill Lynch. This index goes back to 01/31/1997 and contains sovereign bond data for many countries. We decide to work on a sub-sample of 9 countries, namely Australia, Canada, France, Germany, United Kingdom, Italy, Japan, Sweden and United States. Indeed, these countries' bonds are among the most important in terms of trade and issuances, and allow a nice geographical coverage. Each month, we have as of bond constituents, with their characteristics. In order to construct adequate yield curves, we need sovereign yields for a wide range of maturities. Therefore, we build maturity pillars for: 1, 3, 5, 7, 10, 15 and 20 years treasury bonds. More precisely, these indexes are constructed using both the market-weights and a linear weighting in function of the proximity to a pillar: that is a bond maturing in 4 years will participate in both the $3 \mathrm{Y}$ and the $5 \mathrm{Y}$ indexes. Using this method allows limiting gap in these indexes ${ }^{4}$. For each country we estimate the DNS parameters from the following model:

$$
y_{i t}(\tau)=l_{i t}+s_{i t}\left(\frac{1-e^{-\lambda_{i t} \tau}}{\lambda_{i t} \tau}\right)+c_{i t}\left(\frac{1-e^{-\lambda_{i t} \tau}}{\lambda_{i t} \tau}-e^{-\lambda_{i t} \tau}\right)+v_{i t}
$$

Where $y_{i t}$ is the yield of a $\tau$ months maturity bond, $l_{i t}, s_{i t}$ and $c_{i t}$ are respectively the level, slope and curvature factors, $\lambda_{i t}$ an adjustment (or decay parameter) and $v_{i t}$ is the error term ${ }^{5}$. The lower (higher) is the decay rate, the better is the fit of long (short) maturities. This dynamic version of Nelson Siegel model implies that these factors are estimated on a monthly basis. In Figure 1 we plotted the resulting term structure in three dimensions for each country.

Solely on the observation of these term structures, one can concede to the hypothesis that these countries yields movements do share a common pattern: a generally decreasing trend in yields over time, with seemingly additional idiosyncratic shocks to the term structure. Thus we are keen to quantify this (unobserved) global term structure, making the use of state-space modeling particularly suited.

\subsection{Modeling the term structure at the global level}

We follow Diebold et al. (2008)'s paper for the global model formulation, treating the global factors separately. However our approach differs in two points. First, for the global level factor model, we constrain the Eurozone member variance to be equal. We do so in order to account for the unique currency that

\footnotetext{
${ }^{4}$ Still, some data are missing. In this case we proceed as follows: if for a given country, there is a gap for a given maturity series, we exclude this series from the DNS computation. Once the parameters are estimated, we use them to model the missing values for that maturity. This allows obtaining a cylindrical database. Then, in a second round of estimation, we get the new DNS parameters: they are the one we are interested in and that will constitute our inputs for the state-space model estimation.

${ }^{5}$ We recall that equation (1) directly derives from the model specification of forward rates, that is $f(t, \tau)=l_{t}+s_{t} e^{-\lambda_{t} \tau}+c_{t} \lambda_{t} e^{-\lambda_{t} \tau}$ (Bolder, 1999).
} 
Figure 1: Country's Yield Curve

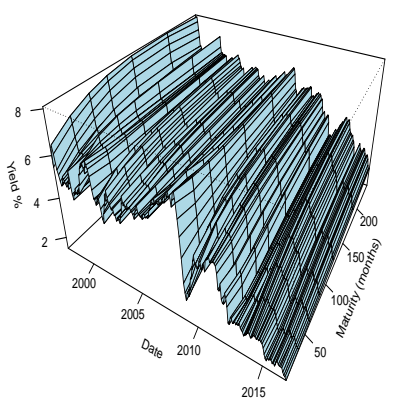

(a) Australia

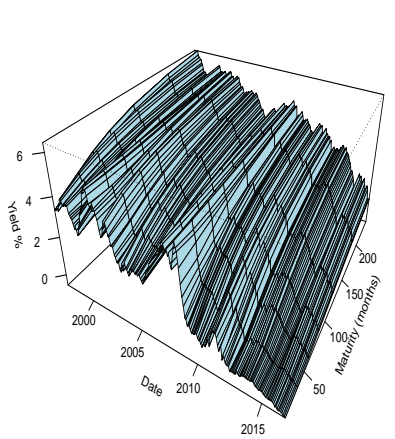

(d) France

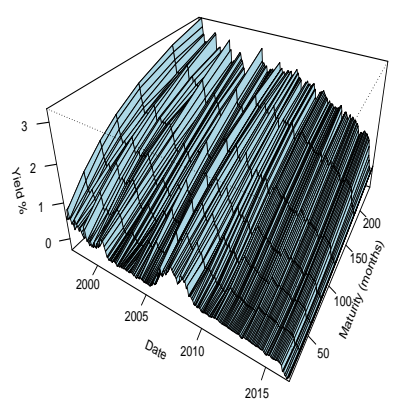

(g) Japan

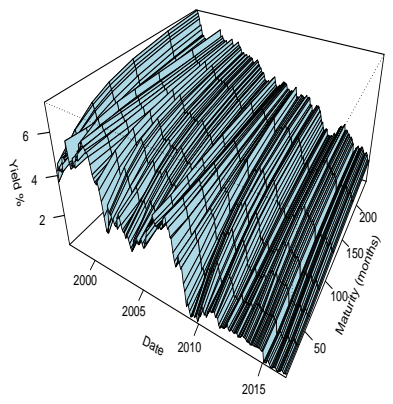

(b) Canada

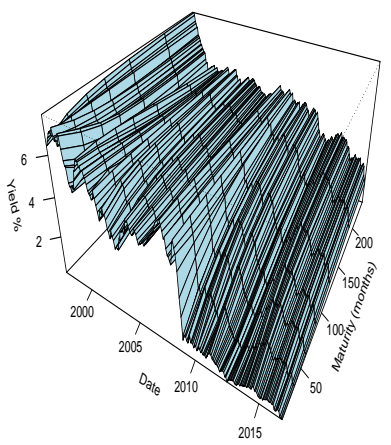

(e) United Kingdom

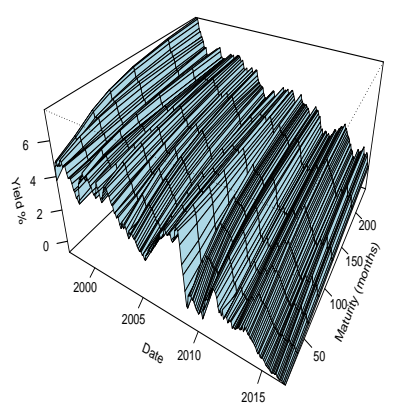

(h) Sweden

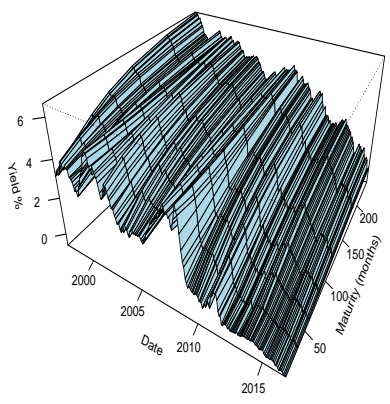

(c) Germany

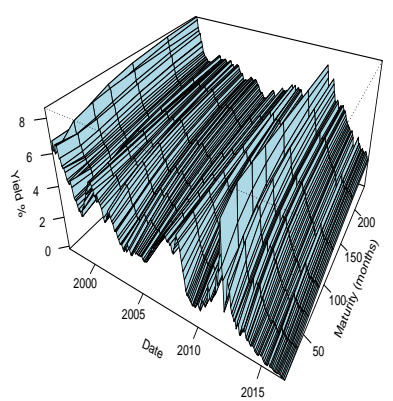

(f) Italy

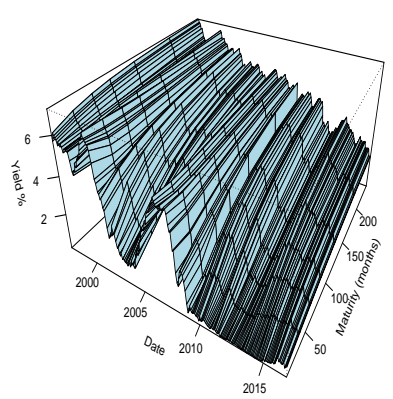

(i) United States

Source: Authors' calculations based on data extracted from BofA ML (sector definition level 3). 
those countries share, and the implications it has in terms of monetary policy. Second, we go beyond their scope of study by estimating a global curvature factor model in the same spirit of the first two ${ }^{6}$. The first round of DNS estimations presented above provide us with level, slope and curvature factors for each country. Below, we formulate three state-space models for the global level, slope and curvature using country-specific factors as inputs.

The global factor can be written as:

$$
L_{t}=\rho L_{t-1}+U_{t}
$$

Where $L_{t}$ is the global factor (either level, slope or curvature depending on the model), modeled by an $A R(1)$ process, with $U_{t} \sim i . i . d N\left(0, \sigma^{2}\right)$.

We decompose each country's factor in a constant $c_{i}$, its interconnection with the global factor noted $\phi_{i}$ and an autoregressive error term $\epsilon_{i t}$. Therefore, for each country $i$ we formulate its (level, slope or curvature) factor as:

$$
\begin{gathered}
l_{i t}=c_{i}+\phi_{i} L_{t}+\epsilon_{i t} \\
\epsilon_{i t}=\Delta_{i} \epsilon_{i t-1}+\nu_{i t}
\end{gathered}
$$

Under matrix representation, the model can be rewritten as:

$$
\begin{gathered}
y_{t}=C+Z \alpha_{t} \\
\alpha_{t}=T \alpha_{t-1}
\end{gathered}
$$

$\mathrm{Z}$ results from the measure equation (5) while $\mathrm{T}, \mathrm{H}$ and $\mathrm{Q}$ follow from the transition equation (6). $\alpha_{t}$ is the state vector, and $y_{t}$ referred to the observed signals.

$$
\mathbf{T}=\left(\begin{array}{cccccccccc}
\rho & 0 & 0 & 0 & 0 & 0 & 0 & 0 & 0 & 0 \\
0 & \Delta_{A U} & 0 & 0 & 0 & 0 & 0 & 0 & 0 & 0 \\
0 & 0 & \Delta_{C A} & 0 & 0 & 0 & 0 & 0 & 0 & 0 \\
0 & 0 & 0 & \Delta_{D E} & 0 & 0 & 0 & 0 & 0 & 0 \\
0 & 0 & 0 & 0 & \Delta_{F R} & 0 & 0 & 0 & 0 & 0 \\
0 & 0 & 0 & 0 & 0 & \Delta_{G B} & 0 & 0 & 0 & 0 \\
0 & 0 & 0 & 0 & 0 & 0 & \Delta_{I T} & 0 & 0 & 0 \\
0 & 0 & 0 & 0 & 0 & 0 & 0 & \Delta_{J P} & 0 & 0 \\
0 & 0 & 0 & 0 & 0 & 0 & 0 & 0 & \Delta_{S E} & 0 \\
0 & 0 & 0 & 0 & 0 & 0 & 0 & 0 & 0 & \Delta_{U S}
\end{array}\right)
$$

\footnotetext{
${ }^{6}$ They argue that the curvature factor might present low precision because of missing data on both short and long ends of maturities and may have poor economic interpretation while Abbritti et al. (2013) state that it relates to future economic uncertainty.
} 


$$
\begin{aligned}
& \mathbf{C}=\left(\begin{array}{c}
c_{A U} \\
c_{C A} \\
c_{D E} \\
c_{F R} \\
c_{G B} \\
c_{I T} \\
c_{J P} \\
c_{S E} \\
c_{U S}
\end{array}\right) \\
&
\end{aligned}
$$

State-space modeling is particularly relevant to our research question in the sense that it allows to model unobserved state variables along with observed signal variables. The model is estimated using the maximum likelihood function and the Kalman filter. This recursive algorithm evaluates the minimum value attained by the Minimum Mean Square Estimate, which is the estimator that minimizes average quadratic error of the state vector conditional on past observations (Koopman et al., 1999). The idea is to replace the parameters in the equations by their estimated value conditional on past observation. In the next period, the set of information available expands and a new value is estimated for the parameters: this allow to compute the prediction error, that would be used in the minimization of the log-likelihood function. Here we employ the Kalman filtering one-step version, rather than the two step version of Diebold and $\mathrm{Li} \mathrm{(2006)}$ as recommended by Diebold et al. (2006). In order to make the Kalman filter converges, we provide starting values obtained from OLS regressions (where we have computed the global factor as a simple average of the 9 countries-specific factors) for signal and state equations. 


\section{Results}

In this section we present the results from the three distinct state-space models. First of all we note most of parameters are significant across models and of expected sign (see Table 2). We observe that all countries except Japan load significantly on the global level factor. This result concerning Japan is not so surprising considering its peculiar, low yield environment, quite disconnected from the other countries composing our sample. Eurozone and North American countries appear to drive this global level factor, while Sweden, Australia and United Kingdom have a lower impact. An analogous argument can be made concerning the global slope factor, while this time Japan does load significantly, with a negative sign on the global factor. Finally, the curve factor is mainly driven by France, Germany, United Kingdom and United States while Canada and Japan do not seem to participate.

Figure 2: Global Level Factor

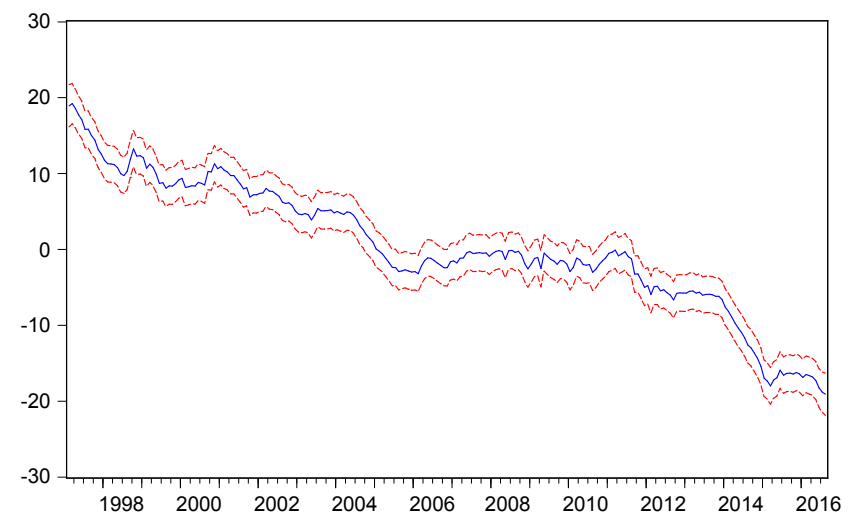

Source: Authors' calculations based on data extracted from BofA ML.

We note that the level factor plotted in Figure 2 shows a decreasing trend over the period, which implies a reduction in yield, a stylized fact for the macroeconomic environment of the past two decades. It has been argued that this factor is closely related to inflation in the sense that yields required by investors will rise when inflationary pressures are at play (Diebold and Li, 2006; Diebold et al., 2008; Abbritti et al., 2013). Additionally, the period we study is altered by unconventional monetary policies which have placed an increased strain on short-term interests, reaching the zero bound in both US and Eurozone. As far as the slope component is concerned (see Figure 3), we can easily distinguish the two recessions of this period, namely the dot com bubble and the subprime crisis. We note that both of these crashes were preceded by strong growth in the 
Table 2: Estimation Results

\begin{tabular}{|c|c|c|c|}
\hline & Level & Slope & Curvature \\
\hline$c_{A U}$ & $5.265^{* * *}$ & $-0.628^{* * *}$ & -73.225 \\
\hline$\phi_{A U}$ & $0.053^{* * *}$ & $0.105^{* * *}$ & $0.419^{* * *}$ \\
\hline$c_{C A}$ & 4.737 & $-2.014^{* * *}$ & -51.352 \\
\hline$\phi_{C A}$ & $0.139 * * *$ & $0.131^{*}$ & 0.286 \\
\hline$c_{D E}$ & 4.718 & $-2.706 * * *$ & -120.155 \\
\hline$\phi_{D E}$ & $0.158^{* * *}$ & $0.249^{* * *}$ & $0.683^{* * *}$ \\
\hline$c_{F R}$ & 4.835 & $-2.736 * * *$ & -135.651 \\
\hline$\phi_{F R}$ & $0.131^{* * *}$ & $0.326^{* * *}$ & $0.770^{* * *}$ \\
\hline$c_{G B}$ & $4.243^{* *}$ & -1.177 & -113.077 \\
\hline$\phi_{G B}$ & $0.070^{* *}$ & $0.099^{* *}$ & $0.653^{* * *}$ \\
\hline$c_{I T}$ & 5.688 & $-3.033^{* * *}$ & -41.168 \\
\hline$\phi_{I T}$ & $0.116^{* * *}$ & $0.386^{* *}$ & $0.228^{* *}$ \\
\hline$c_{J P}$ & $4.226^{* * *}$ & $-4.008 * * *$ & -54.277 \\
\hline$\phi_{J P}$ & -0.029 & $-0.061 * * *$ & $0.295^{* *}$ \\
\hline$c_{S E}$ & 4.213 & $-1.748 * * *$ & -58.695 \\
\hline$\phi_{S E}$ & $0.080 * *$ & $0.180^{* * *}$ & 0.335 \\
\hline$c_{U S}$ & 5.200 & $-2.653^{* *}$ & -95.952 \\
\hline$\phi_{U S}$ & $0.112^{* * *}$ & $0.124^{* * *}$ & $0.541^{* * *}$ \\
\hline$\rho$ & $0.998^{* * *}$ & $0.947^{* * *}$ & $1.000^{* * *}$ \\
\hline$\Delta_{A U}$ & $0.489^{* * *}$ & $0.610^{* * *}$ & $0.431^{* * *}$ \\
\hline$\nu_{A U}$ & $0.516^{* * *}$ & $0.655^{* * *}$ & $7.705^{* * *}$ \\
\hline$\Delta_{C A}$ & $0.738^{* * *}$ & $0.846^{* * *}$ & $0.801^{* * *}$ \\
\hline$\nu_{C A}$ & $0.110 * * *$ & $0.342^{* * *}$ & $2.429 * * *$ \\
\hline$\Delta_{D E}$ & $0.833^{* * *}$ & $0.905^{* * *}$ & $0.351^{* * *}$ \\
\hline$\nu_{D E}$ & $0.233^{* * *}$ & $0.116^{* * *}$ & 0.976 \\
\hline$\Delta_{F R}$ & $0.709 * * *$ & $0.914^{* * *}$ & $-0.216^{* * *}$ \\
\hline$\nu_{F R}$ & $0.233^{* * *}$ & $0.072^{* * *}$ & $0.304^{* * *}$ \\
\hline$\Delta_{G B}$ & $0.799 * * *$ & $0.951^{* * *}$ & $0.684^{* * *}$ \\
\hline$\nu_{G B}$ & $0.262^{* * *}$ & $0.400 * * *$ & $3.757^{* * *}$ \\
\hline$\Delta_{I T}$ & $0.514^{* * *}$ & $0.077 * * *$ & $0.226^{* * *}$ \\
\hline$\nu_{I T}$ & $0.233^{* * *}$ & $0.303^{* * *}$ & $7.559^{* * *}$ \\
\hline$\Delta_{J P}$ & $0.797^{* * *}$ & $0.817^{* * *}$ & $0.762^{* * *}$ \\
\hline$\nu_{J P}$ & $0.724^{* * *}$ & $0.817 * * *$ & 1.173 \\
\hline$\Delta_{S E}$ & $0.761^{* * *}$ & $0.808^{* * *}$ & $0.651^{* * *}$ \\
\hline$\nu_{S E}$ & $0.764^{* * *}$ & 0.946 & $6.419^{* * *}$ \\
\hline$\Delta_{U S}$ & $0.462^{* * *}$ & $0.963^{* * *}$ & $0.828^{* * *}$ \\
\hline$\nu_{U S}$ & $0.078^{* * *}$ & $0.163^{* * *}$ & $1.735^{* * *}$ \\
\hline
\end{tabular}


Figure 3: Global Slope Factor

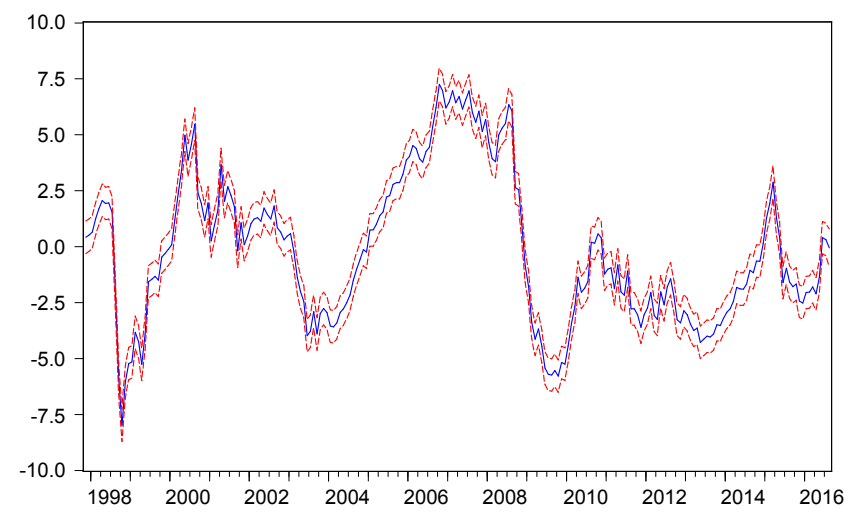

Source: Authors' calculations based on data extracted from BofA ML.

Figure 4: Global Curvature Factor

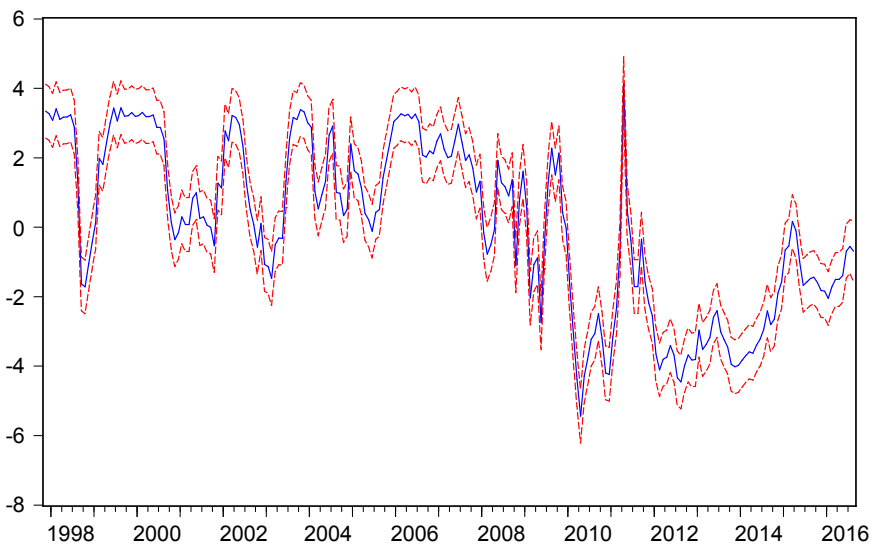

Source: Authors' calculations based on data extracted from BofA ML.

slope factor (that is short yields increasing more than long yields), a standard observation in the literature which often conduces to assimilating this factor to economic activity. (Diebold and Li, 2006; Diebold et al., 2008; Abbritti et al., 2013). Indeed, in relation with the level component, when central banks set interest rate above (below) market consensus, inflation expectations will fall (rise) which in turn will flatten (steepen) the yield curve. Finally, the curvature factor represented in Figure 4 is less persistent than the first two, in line with the literature (Diebold and $\mathrm{Li}, 2006$ ). The most striking feature is perhaps the 
successive jumps between 2008 and 2011, a period of high uncertainty. After a peak in August 2009 the global curvature hits rock-bottom in April 2010, which means that short-long ends yields have moved substantially after being followed by the medium-term rates. A new peak is attained a year later. While some authors argue that this factor may lack of economic interpretation (Diebold et al., 2008) some others assimilate it to a predictor of economic instability (Abbritti et al., 2013). While our results support the existence of a link between this factor and economic and financial uncertainty, we cannot conclude regarding its ability to predict future periods of instability. As a matter of fact, these parameters can be summed up in a 3D plot, see Figure 5. In the light of Figure 1, this is in fact the common component that we have extracted from country-level term structures using the state-space framework. We note that once again, level factor seems to prevail.

Figure 5: Global Yield Curve

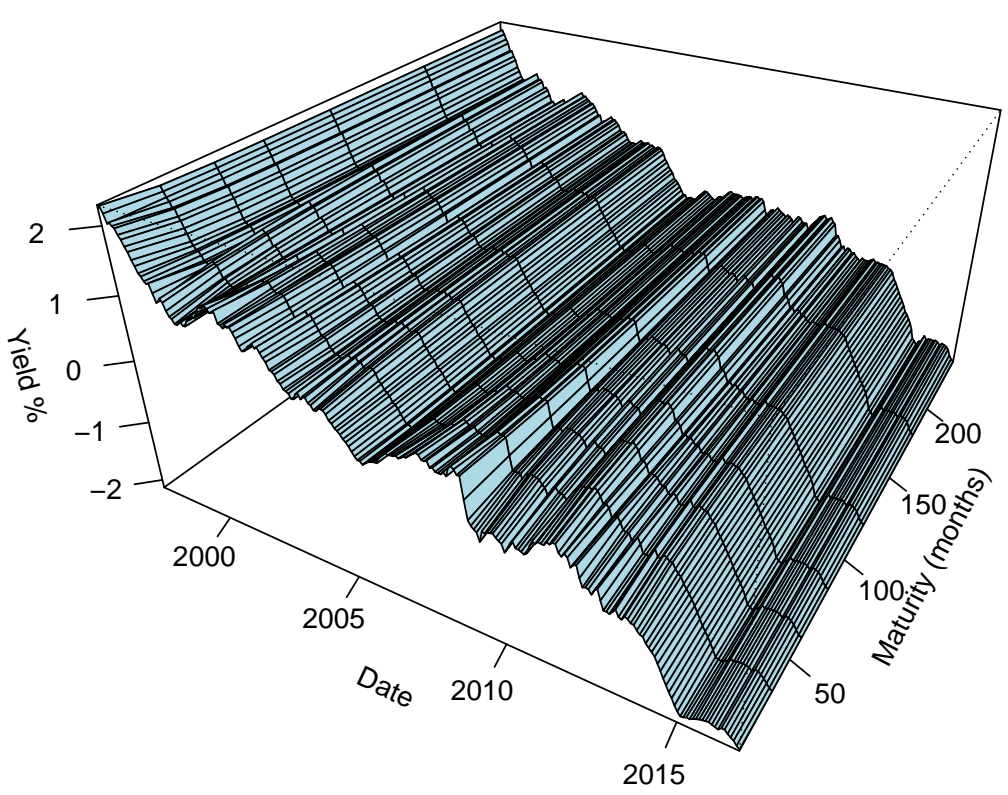

Source: Authors' calculations based on data extracted from BofA ML.

Thus, we are now able to re-compute ex-post the part of each country's yield that is explained by global term structure fluctuations. Indeed, combining the coefficients associated to each country with the estimated global factors at each date, we are able to construct a series for each country/maturity pair and to decompose yields according to global level, slope and curvature components. We fix $\lambda=0.0609$ as in Diebold and Li (2006). We can thus rewrite the global model implied yield as: 
where Yield $_{i, \tau, t}$ is the global model implied yield of a bond with $\tau$ maturity from country $i$ at date $t$ while $\phi_{i}^{L}, \phi_{i, \tau}^{S}$ and $\phi_{i, \tau}^{C}$ are respectively the sensitivity of country $i$ to global level, slope and curvature fluctuations ${ }^{7}$.

For an illustrative purpose, model implied 10 years yields have been computed for each country and are presented in Figure 8 in Appendix. We are able to identify some key stylized facts at the country level from this exercise. More precisely, these countries do no share the same inflationary pressure nor credit event risk. Overall Italy has the highest yield and Japan the lower, as expected. Deflationary movements observed in Japan also come out here, with the smallest variations in yield over the period. Similarly, the global drop in inflation figures that occurred in 2012 is also well captured in our yield model. Some other interesting observations emanate from this exercise: general yields level has decreased over the period, the slope factor remains relatively constant over the period for each country (except a notable tightening in 2007 in the Eurozone meaning that short-term yields have stopped moving substantially more than long-term yields) while the curvature factor appears to be particularly active since the crisis, implying that medium-term yields have decreased more than short and long-term yields: the global term structure lost in convexity and flattened. These results corroborate the PCA results: first we observe that level risk does account for most of the variability in yields. Second, the term structure distortions reflected in Figure 5, namely the decreasing trend in yields over the period, the overreaction of short-term yields compared to their long counterparts between 2004 and 2007 and the recent flattening all come out in our re-computation of 10 years model implied yields. Thus we argue the the global term structure model we propose allows to explain fairly well the past decades stylized facts. Last but not least, it authenticates the existence of a global term structure in our sample, augmented with idiosyncratic country characteristics.

\section{Application : incorporating global term struc- ture risk in index design}

After providing evidences supporting the existence of a term structure at the global scope, we are keen to exploit it in risk management framework from the point of view of a fixed-income investor. More specifically, in this section we propose two novel indexing schemes in a risk parity framework, see Table 3. As recalled by Maillard et al. (2010) Equal Risk Contribution is actually the most straightforward implementation of the risk parity philosophy: the idea is to set an asset weight inversely proportional to its risk. The risk measure employed here is the exposure to global interest rate risk, that is variations

\footnotetext{
${ }^{7}$ More precisely, $\phi_{i, \tau}^{S}=\phi_{i}^{S}\left(\frac{1-e^{-\lambda} i t \tau}{\lambda_{i t} \tau}\right)$ and $\phi_{i, \tau}^{C}=\phi_{i}^{C}\left(\frac{1-e^{-\lambda_{i t} \tau}}{\lambda_{i t} \tau}-e^{-\lambda_{i t} \tau}\right)$
} 
in the global term structure. To our knowledge, this is the first time that a depart from credit risk towards interest rate risk occurs in the implementation of a risk parity scheme for Treasury bonds. Indeed, in the sovereign bond universe, and more specifically in our sample of developed countries, interest rate risk is more likely to prevails on credit risk. The first proposal we make is to weight countries in function of their exposure to the global level risk in lieu of their market capitalization. A second application directly related to the global term structure modeling consists in weighting buckets of maturities within a given country in function of their global level risk, augmented with non parallel global risks (slope and curvature). Indeed, if the level (parallel) risk does not vary across maturities, and hence is unique for a given country, slope and curvature (non-parallel) risks do. Slope risk usually decreases with maturity, while curvature risk is more pronounced for medium-term maturities. Therefore the first method we propose allows discriminating between countries while the second attributes weights within a country by differentiating across buckets of maturities. In order to disentangle these two effects, we first present them separately, while introducing their conjunctive use in the last part of this section.

Table 3: Four Strategies

\begin{tabular}{lcccc}
\hline & CW & $\begin{array}{c}\text { Country } \\
\text { parity }\end{array}$ & $\begin{array}{c}\text { Bucket } \\
\text { parity }\end{array}$ & $\begin{array}{c}\text { Country bucket } \\
\text { parity }\end{array}$ \\
\hline Country allocation & $\mathrm{CW}$ & $\mathrm{ERC}$ & $\mathrm{CW}$ & ERC \\
Bucket allocation & $\mathrm{CW}$ & $\mathrm{CW}$ & $\mathrm{ERC}$ & ERC \\
Bond allocation & $\mathrm{CW}$ & $\mathrm{CW}$ & $\mathrm{CW}$ & $\mathrm{CW}$ \\
\hline \multicolumn{4}{c}{ Notes: ERC stands for Equal Risk Contribution and CW for Capitalization } \\
Weighting.
\end{tabular}

We work on the W0G1 and study the same subset of developed countries as in Section 2 (Australia, Canada, Germany, France, United Kingdom, Japan, Italy, United States and Sweden). To sum up our index design strategy, we recall that one first needs to compute each country's individual DNS parameters. Then, solving for the three distinct global state-space models using the Kalman filter allows to extract each country/maturity exposure to global interest rate risk variations. These "global" DNS parameters are then used to re-compute the "global model implied" yield for each country/maturity pairs, which is the part of the yield that is attributable to global term structure movements. Up to $01 / 31 / 2010$ we assume those coefficients constant, however in order to avoid forward bias, we choose to test the state-space models' out-of-sample performance. We proceed as follows: we use the period 01/31/1997-01/31/2010 to "calibrate" the model and at the end of January 2010 we use the estimated exposure to the global factors when re-balancing the index ${ }^{8}$. Then each year, we add up the

\footnotetext{
${ }^{8}$ The exposures to global factors used in our computation are presented in Appendix, Figures 9-11. In lines with the global factors obtained from the state-space modeling exercise,
} 
observations within the state-space models and reestimate the parameters. To illustrate at the end of January 2011, to re-balance the portfolio we compute the coefficients on the period 01/31/1997-01/31/2011. In that sense, the strategies we present are dynamic, still forward bias free. We use such "rolling" scheme for two reasons: first, our model needs sufficient data in order to estimate the 37 coefficients that compose each one of our state-space models, for instance a rolling period of 3 years would only provides $3 \times 12$ observations for each state variable. Second, we argue that our approach is rather focused on structural determination of global interest risk, and in that sense, that the more observation the better. Indeed, we are not in a tactical approach: we rather want to estimate robust exposures to the global term structure.

We build a first index called "country parity", where countries exposure to the global level factor are equalized. It implies that we only modify countries weights, and then within a country we reallocate weights in the same manner as the cap-weighted benchmark. We make the hypothesis of equal off-diagonal block elements in the correlation structure in the spirit of Disatnik and Katz (2012). To discriminate across countries, parallel shifts are sufficient, but non parallel shifts have to be accounted for when allocating assets across different buckets of maturities. This is the reason why we present a second indexing scheme entitled "bucket parity": this time, we keep the cap-weights at the country level, but then within a country we set weights in function of the exposure of each bucket to global interest rate risk (that incorporates level, slope and curvature), assuming equal correlation between maturities buckets within a country. Finally, we present a third index that mixes up the two strategies above: this is the "country bucket parity index". From an analytical point of view, the optimization problem to find weights that achieve ERC can be written as:

$$
\begin{array}{ll}
\underset{w_{i}}{\operatorname{minimize}} & \sum_{i=1}^{N}\left(R C_{i}-\overline{R C_{i}}\right)^{2} \\
\text { subject to } & \sum_{i=1}^{N} w_{i}=1
\end{array}
$$

where $R C_{i}=w_{i}\left(R_{i}\right)$

In the case of the "country parity" index, $i$ denotes the country and $R_{i}=L_{i}$. For the "bucket parity" index, $i$ denotes the maturity of a bond and $R_{i}=$ $L+S_{i}+C_{i}$ (because the level factor is unique for a country, constant across maturities). As far as the "country bucket parity" is concerned, it simply consists in solving this optimization program twice, at the country and bucket levels that are mutually independent. Following this approach, we re-balance the index once a year at the end of January by computing the country (bucket) exposure to the global factor(s), which is simply the product of a country (bucket) sensi-

exposures are quite steady across time (See Figures 9 and 10) compared to those of the curvature factor (Figure 11). 
tivity and the modeled global level (slope and curvature factors). Then we let the weights drift with market movements. We provide an illustrative example of the "bucket parity" setting in Appendix, Table 5, for Japan in 2000, where interest rate risk exposure can be observed across different maturity buckets. The backtest results for the country parity, the bucket parity and the country bucket parity indexes are presented in Figure 6 alongside with the cap-weighted benchmark.

Figure 6: Backtests Results, Total Rate of Returns

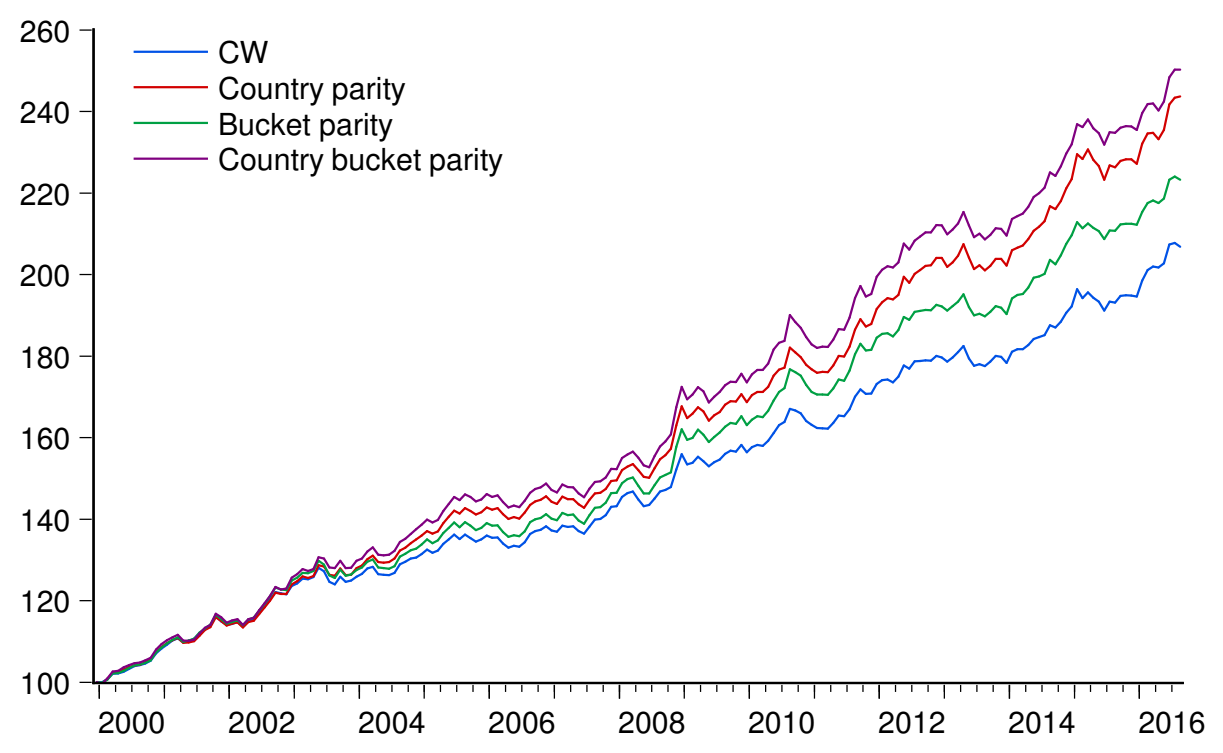

Notes: Vertical axis represents index value, with base $100=12 / 31 / 1999$ Source: Authors' calculations based on data extracted from BofA ML.

Switching from capitalization weighting towards interest rate risk management clearly leads to a very different outcome in terms of backtests. The first noteworthy result in Figure 6 is perhaps the gains in performance observed for all the three indexes proposed. Turning to Table 4 to appraise more formally these enhancements, a couple of points can be raised. Re-weighting countries by equalizing their exposure to global interest rate risks allows notable gains in terms of risk-adjusted returns metrics: the increase in returns is more significant than the rise in volatility, leading to an enhanced Sharpe ratio of 0.75 compared to 0.49 for the cap-weighted benchmark while Treynor ratio is also improved. Despite unchanged rating, it appears that changing country weights but then keeping the same debt structure as the cap-weighted benchmark leads to a larger loading on credit risk as shown by the higher spread. One could argue that the ERC scheme implies overweighting countries the least sensible to 
Table 4: Backtests Results

\begin{tabular}{lcccc}
\hline & CW & $\begin{array}{c}\text { Country } \\
\text { parity }\end{array}$ & $\begin{array}{c}\text { Bucket } \\
\text { parity }\end{array}$ & $\begin{array}{c}\text { Country bucket } \\
\text { parity }\end{array}$ \\
\hline Total returns & $107 \%$ & $144 \%$ & $123 \%$ & $150 \%$ \\
Ann. total returns & $4.46 \%$ & $5.49 \%^{* * *}$ & $4.94 \%^{* * *}$ & $5.66 \%^{* * *}$ \\
Volatility & $2.95 \%$ & $3.31 \%^{*}$ & $3.24 \%^{*}$ & $3.51 \% * * *$ \\
Sharpe ratio & 0.49 & 0.75 & 0.60 & 0.76 \\
Information ratio & - & 1.18 & 0.77 & 1.09 \\
TE & - & $0.88 \%$ & $0.62 \%$ & $1.10 \%$ \\
Treynor ratio & 1.46 & 2.30 & 1.79 & 2.34 \\
Maximum drawdown & $-3.18 \%$ & $-3.40 \%$ & $-3.57 \%$ & $-4.23 \%$ \\
Duration & 6.41 & 6.32 & 6.56 & 6.42 \\
Rating & $\mathrm{AAA}$ & $\mathrm{AAA}$ & $\mathrm{AA}$ & $\mathrm{AAA}$ \\
Spread & 7.59 & 12.07 & 8.71 & 12.21 \\
Years to maturity & 8.32 & 8.51 & 8.62 & 8.62 \\
\hline
\end{tabular}

Notes: The benchmark refers to the capitalization-weighted index from Merrill Lynch. 12 months T-bill yields were averaged over the study period to obtain a risk-free rate of $3 \%$. Sharpe ratio corresponds to the return of the portfolio minus the risk-free rate, divided by the standard deviation of the returns while the information ratio is the returns above divided by the tracking error (TE). We have computed the p-values for differences from the benchmark, using a paired t-test for the monthly returns, and a Fisher test of equality of variances. (Annualized) tracking error is the standard deviation of the difference between the returns of a portfolio and a given benchmark. Treynor ratio represents the difference between the return of a portfolio and the risk free rate, divided by its beta (so adjusted from duration risk). Ratings were computed from Morningstar's (c) methodology.

$* * *$ Significant at $1 \%$,

** Significant at $5 \%$,

* Significant at $10 \%$

Source: Authors' calculations based on data extracted from BofA ML. 
global variations in the term structure, which is basically being long on smaller countries such as Sweden and Australia compared to the benchmark. This bet might be held responsible for the apparent deterioration in credit quality. The bucket parity index also achieves higher risk-adjusted metrics, but in a lesser extent. An interesting result is that the bucket parity appears to bring about a small "quality" tilt as shown by the gain in rating. Finally, the conjunctive use of an ERC scheme on both countries and bucket clearly leads to the best outcome: total returns are significantly enhanced and both Sharpe and Treynor ratios are maximized when we apply these two layers. Last but not least, since short-term bonds are often considered less risky, one could have feared that applying an ERC scheme using an interest rate risk metric would have led to a drastic reduction in the maturity of the index. Our backtests results go against that hypothesis, as demonstrated by the small deformation in duration and time to maturity compared to the cap-weighted benchmark.

Figure 7: Average Country Weights

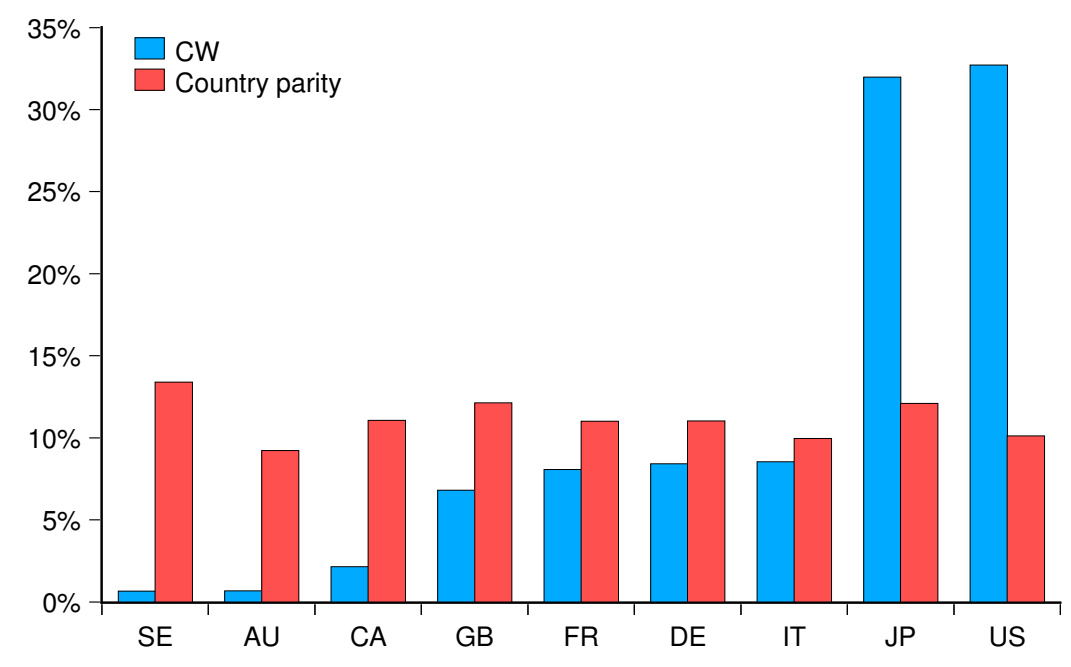

Source: Authors' calculations based on data extracted from BofA ML.

Figure 7 indicates that an equal interest rate risk contribution scheme on the country level produces an under-weighting of both US and Japan in favor of the other countries constituting our sample. We believe that this distortion may explain the spread differentials. If on average country weights appear fairly equals, they do evolve more dynamically over time as presented in Figure 12 in Appendix, this argument being the most relevant after 2014. 
In an interest rate risk parity framework, it appears of prime concern to evaluate the robustness of the strategies we implement to variations in the economic environment, and more precisely chancing interest rate regimes. This idea is reinforced by the expectations that both the FED and the European Central Bank will soon put an end to their quantitative easing policies. Working on global indexes, composed of major bond issuing developed countries, we choose to use the US T-bill rates to discriminate between these periods. Results are presented below in Table 5 .

Table 5: Performance across interest rate regimes

\begin{tabular}{|c|c|c|c|c|c|}
\hline & & $\mathrm{CW}$ & $\begin{array}{l}\text { Country } \\
\text { parity }\end{array}$ & $\begin{array}{l}\text { Bucket } \\
\text { parity }\end{array}$ & $\begin{array}{c}\text { Country bucket } \\
\text { parity }\end{array}$ \\
\hline \multirow{5}{*}{ 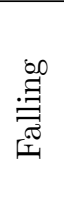 } & Ann. total returns & $4.65 \%$ & $5.24 \%$ & $4.93 \%$ & $5.43 \%$ \\
\hline & Volatility & $3.18 \%$ & $3.26 \%$ & $3.27 \%$ & $3.37 \%$ \\
\hline & Sharpe ratio & 0.52 & 0.69 & 0.59 & 0.72 \\
\hline & TE & - & $0.66 \%$ & $0.27 \%$ & $0.79 \%$ \\
\hline & Treynor ratio & 1.65 & 2.21 & 1.98 & 2.46 \\
\hline \multirow{5}{*}{ 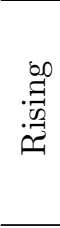 } & Ann. total returns & $4.76 \%$ & $5.54 \%$ & $4.36 \%$ & $5.13 \%$ \\
\hline & Volatility & $2.49 \%$ & $2.68 \%$ & $2.32 \%$ & $2.46 \%$ \\
\hline & Sharpe ratio & 0.71 & 0.95 & 0.59 & 0.87 \\
\hline & TE & - & $0.75 \%$ & $0.75 \%$ & $0.93 \%$ \\
\hline & Treynor ratio & 1.76 & 2.47 & 1.53 & 2.33 \\
\hline \multirow{5}{*}{$\stackrel{0}{\stackrel{0}{N}}$} & Ann. total returns & $4.02 \%$ & $5.46 \%$ & $4.34 \%$ & $5.40 \%$ \\
\hline & Volatility & $3.05 \%$ & $3.74 \%$ & $3.03 \%$ & $3.54 \%$ \\
\hline & Sharpe ratio & 0.33 & 0.66 & 0.44 & 0.68 \\
\hline & $\mathrm{TE}$ & - & $0.99 \%$ & $0.70 \%$ & $1.01 \%$ \\
\hline & Treynor ratio & 1.02 & 2.04 & 1.38 & 2.14 \\
\hline
\end{tabular}

Notes: The benchmark refers to the capitalization-weighted index from Merrill Lynch. 12 months T-bill yields were averaged over the study period to obtain a risk-free rate of $3 \%$. Sharpe ratio corresponds to the return of the portfolio minus the risk-free rate, divided by the standard deviation of the returns while the information ratio is the returns above divided by the tracking error (TE). (Annualized) tracking error is the standard deviation of the difference between the returns of a portfolio and a given benchmark. Treynor ratio represents the difference between the return of a portfolio and the risk free rate, divided by its beta (so adjusted from duration risk). Phases were identified qualitatively: rising T-Bill rate regime corresponds to periods from 09/30/1998 to 10/31/2000, 05/31/2004$02 / 28 / 2007$ and since 09/30/2015. Falling T-bill rate regime corresponds to $12 / 31 / 1996$ 08/31/1998, 11/30/2000-04/30/2004 and 03/31/2007-08/31/2008. Between 09/30/2008 and $09 / 30 / 2015$ we consider that we are in the zero T-bill rate regime.

Source: Authors calculations based on data extracted from BofA ML. We also use the 3 months T-bill Secondary Market from the Federal Reserve Bank of St Louis database.

This analysis on changing rate environment provides several interesting insights. First of all, when turning to risk-adjusted returns metrics (the Sharpe and the Treynor ratio) out-performance remains across the three distinct regimes. Second, although under both the falling and zero spread regimes we note that the country bucket parity index performs significantly better than the country parity index (ie: global non-parallel interest rate risk management does add 
value), under a rising rate the latter gives the best results. However, some caution must be given to this result: turning to Figure 1 and Figure 8 in Appendix, the successive periods of rising rates faced in the sample (between 1998 and 2000 and then between 2004 and 2007) generally did not coincide with the largest non-parallel deformation in the country's yield curves. Thus, discarding non-parallel shift management in the coming years may reveal to be hazardous if the rise in rates leads to twists in the term structure.

We can draw several concluding remarks from this exercise: while the equal interest rate risk contribution scheme appears to bring about significant improvements in a risk/return framework when applied at the country or bucket level, enhancements are maximized when focusing on discriminating between countries. Recalling that the latter only focuses on managing parallel shifts in the global term structure, this result is not surprising. Indeed, as suggested in Table 1 and corroborated by the Figure 8 in Appendix, level risk outstrips non parallel risks, accounting for more than $80 \%$ of total interest rate risk. In that sense, managing country weights within an index implies controlling most of the interest rate risk. In addition, even though the bucket parity index is appealing on its own, its benefits are enhanced when used in conjunction with an ERC at the country level. Switching away from country cap-weights is a sensible approach because it allows to manage the prime source of risk in the sovereign bonds universe, however accounting for the non-parallel shifts in the global term structure heightens the benefits of the pure "country parity" scheme.

\section{Conclusion}

In the first part of this paper, relying on Dynamic Nelson Siegel estimation we present some preliminary analysis of the yields across main developed countries. Overall, the latter appears to support the existence of a global term structure. To formally capture such yield curve dynamics we turn over state-space modeling using the country-level parameters as inputs, distinguishing between level, slope and curvature factors. By doing so, we go further than Diebold et al. (2008): first we expand the country sample and second we consider the existence of a curvature factor at the global scale in the spirit of Abbritti et al. (2013). Such exercise allows to replicate observed stylized facts fairly well, and on top of that permits to quantify countries linkages to a global yield curve owing to the estimates obtained from the Kalman filter.

The second part of this paper investigates how the global term structure can be incorporated into the design of risk parity index. To our knowledge this is the first time that such models are used within a risk parity framework. As a matter of fact, considering interest rates within the latter is also innovative, credit risk being generally employed when equalizing risk contribution across assets. More specifically, two new sovereign bond indexing schemes are pre-

sented: for the first one we equalize the exposure of a country to variations of 
the global level factor, while for the second we equalize the exposure of maturity buckets to non-parallel fluctuations in the global term structure. We show that parallel shifts should be of prime interest in interest rate risk management. Finally, we introduce the conjunctive use of these two strategies in a third index.

These three indexes produce superior risk-adjusted performance, the latter being maximized for the index which manages both parallel and non-parallel shifts in the global yield curve. We conclude that interest rate parity is relevant for developed -investment grade- countries and that exposure to global yield curve movements is a suitable metric to use in such framework. Additionally, the latter could be used in a wide range of applications on top of indexing: hedging strategies for instance could be developed on those grounds. 


\section{References}

M. Abbritti, S. Dell'Erba, A. Moreno, and S. Sola. Global factors in the term structure of interest rates. Avalaible at SSRN, 2013.

J. Bai and P. Wang. Identification and estimation of dynamic factor models. Technical report, University Library of Munich, Germany, 2012.

T. Björk and B.J. Christensen. Interest rate dynamics and consistent forward rate curves. Mathematical Finance, 9(4):323-348, 1999.

D. Bolder, D.J.and Stréliski. Yield curve modelling at the bank of canada. Available at SSRN, 1999.

J.Y. Campbell and R.H. Clarida. The term structure of euromarket interest rates: An empirical investigation. Journal of Monetary Economics, 19(1): $25-44,1987$.

J.C. Cox, J.E. Ingersoll Jr, and S.A. Ross. A theory of the term structure of interest rates. Econometrica: Journal of the Econometric Society, pages $385-407,1985$.

M. Dahlquist and H. Hasseltoft. International bond risk premia. Journal of International Economics, 90(1):17-32, 2013.

F.X. Diebold and C. Li. Forecasting the term structure of government bond yields. Journal of Econometrics, 130(2):337-364, 2006.

F.X. Diebold, G.D. Rudebusch, and S.B. Aruoba. The macroeconomy and the yield curve: a dynamic latent factor approach. Journal of Econometrics, 131 (1):309-338, 2006.

F.X. Diebold, C. Li, and V.Z. Yue. Global yield curve dynamics and interactions: a dynamic nelson-siegel approach. Journal of Econometrics, 146(2):351-363, 2008.

D. Disatnik and S. Katz. Portfolio optimization using a block structure for the covariance matrix. Journal of Business Finance $\&$ Accounting, 39(5-6): 806-843, 2012.

M. Dungey, V.L. Martin, and A. Pagan. A multivariate latent factor decomposition of international bond yield spreads. Journal of Applied Econometrics, 15(6):697-715, 2000.

S.J. Koopman, N. Shephard, and J.A. Doornik. Statistical algorithms for models in state space using ssfpack 2.2. The Econometrics Journal, 2(1):107-160, 1999.

S. Lardic, P. Priaulet, and S. Priaulet. Pca of the yield curve dynamics: questions of methodologies. Journal of bond trading and management, 1(4):327$349,2003$. 
Robert B Litterman and Jose Scheinkman. Common factors affecting bond returns. The Journal of Fixed Income, 1(1):54-61, 1991.

S. Maillard, T. Roncalli, and J. Teïletche. The properties of equally weighted risk contribution portfolios. The Journal of Portfolio Management, 36(4): 60-70, 2010.

L. Martellini and P. Priaulet. Fixed-Income Securities: Dynamic Methods for Interest Rate Risk Pricing and Hedging. Wiley, 2000.

J.H. McCulloch. Measuring the term structure of interest rates. The Journal of Business, 44(1):19-31, 1971.

J.H. McCulloch. The tax-adjusted yield curve. The Journal of Finance, 30(3): 811-830, 1975.

C.R. Nelson and A.F. Siegel. Parsimonious modeling of yield curves. Journal of business, pages 473-489, 1987.

G.D. Rudebusch. Macro-finance models of interest rates and the economy. The Manchester School, 78(s1):25-52, 2010.

L.E.O. Svensson. Estimating and interpreting forward interest rates: Sweden 1992-1994. Technical report, National bureau of economic research, 1994.

O. Vasicek. An equilibrium characterization of the term structure. Journal of financial economics, 5(2):177-188, 1977.

O. Vasicek and H.G. Fong. Term structure modeling using exponential splines. The Journal of Finance, 37(2):339-348, 1982. 


\section{Appendix}

\subsection{Exposure of 10 years yields to global factors}

Figure 8: 10 Years Yield Decomposition

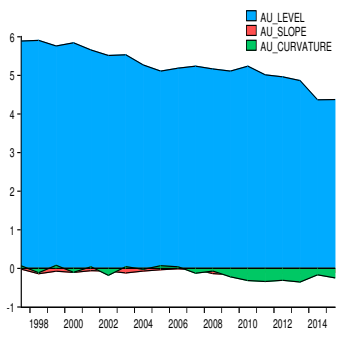

(a) Australia

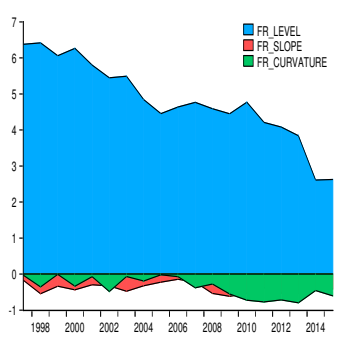

(d) France

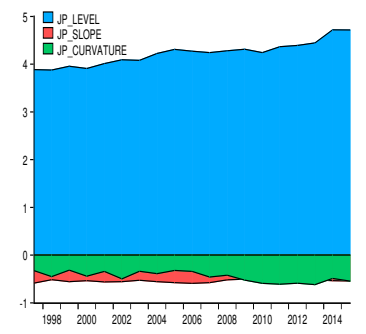

(g) Japan

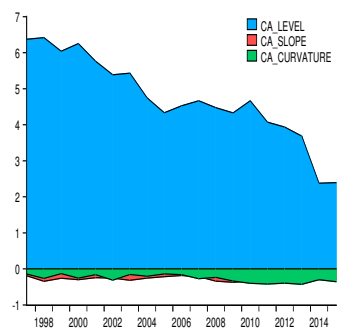

(b) Canada

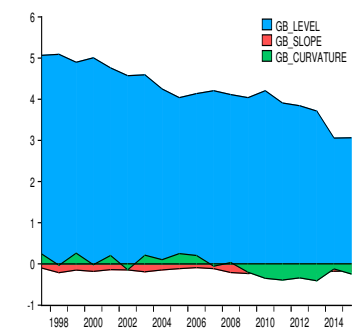

(e) United Kingdom

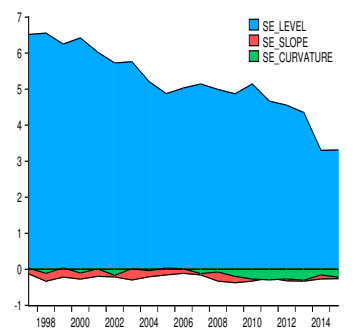

(h) Sweden

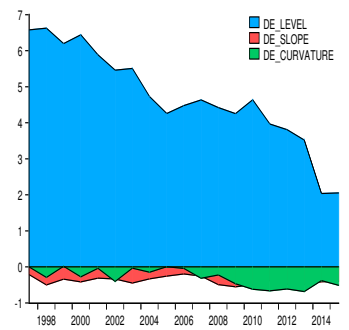

(c) Germany

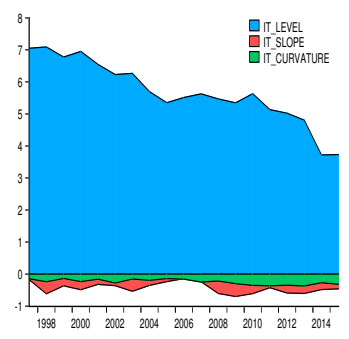

(f) Italy

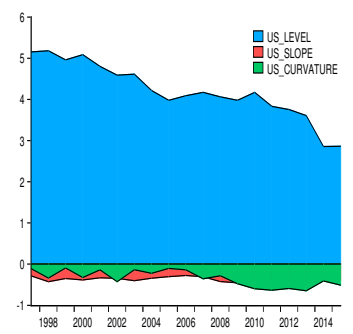

(i) United States

Source: Authors' calculations based on data extracted from BofA ML. 


\subsection{Country exposure to global yield movements}

Figure 9: Exposure to Global Level Factor

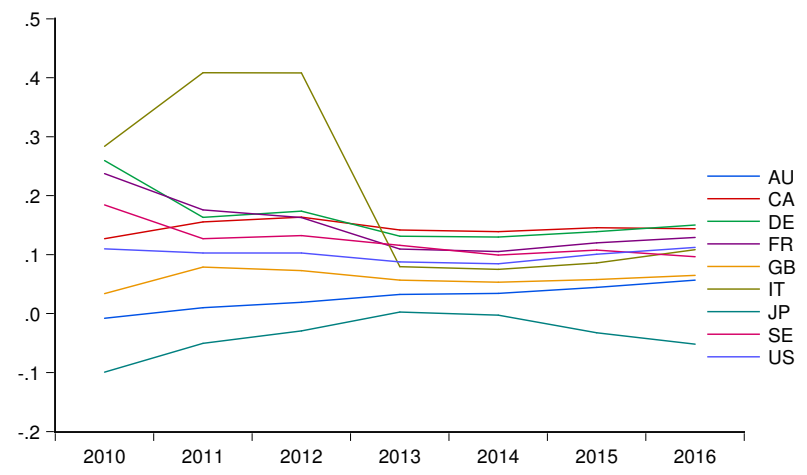

Source: Authors' calculations based on data extracted from BofA ML.

Figure 10: Exposure to Global Slope Factor

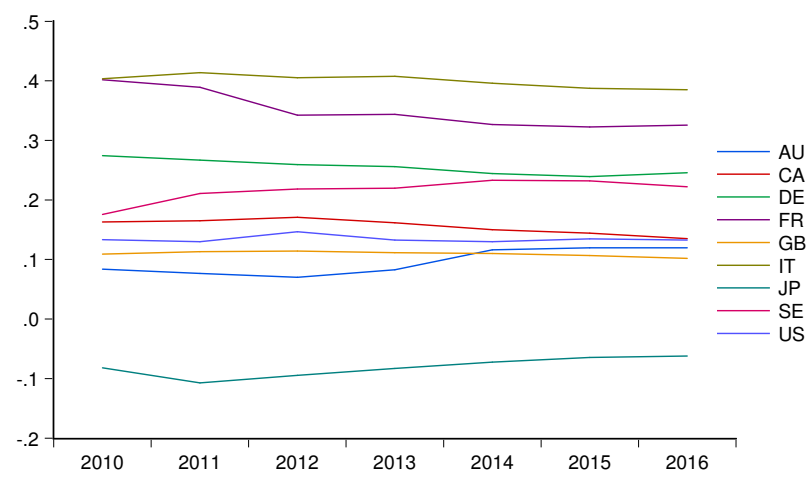

Source: Authors' calculations based on data extracted from BofA ML. 
Figure 11: Exposure to Global Curvature Factor

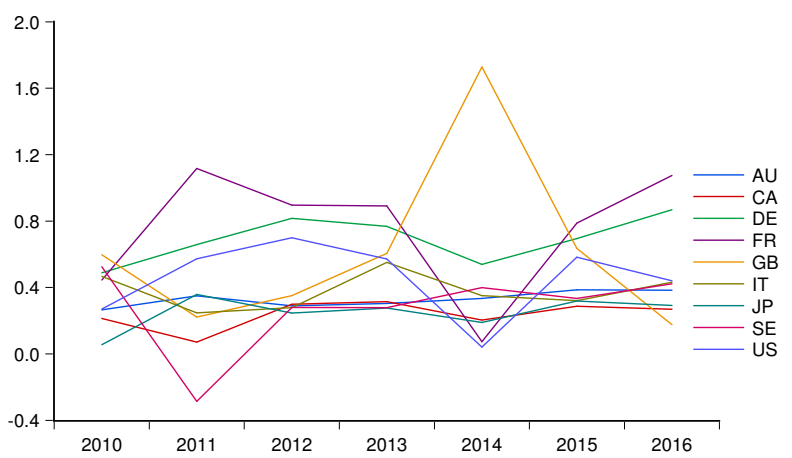

Source: Authors' calculations based on data extracted from BofA ML.

\subsection{Exposure to global factors across maturities - Japan}

Table 6: Japan Interest Rate Risk Across Maturities

\begin{tabular}{lcccc}
\hline Asset & $\begin{array}{c}\text { Level } \\
\text { risk }\end{array}$ & $\begin{array}{c}\text { Slope } \\
\text { risk }\end{array}$ & $\begin{array}{c}\text { Curvature } \\
\text { risk }\end{array}$ & $\begin{array}{c}\text { Total interest } \\
\text { rate risk }\end{array}$ \\
\hline$J P_{12 M}$ & 3.95 & -2.88 & -0.53 & 0.54 \\
$J P_{36 M}$ & 3.95 & -1.65 & -0.68 & 1.63 \\
$J P_{60 M}$ & 3.95 & -1.08 & -0.56 & 2.31 \\
$J P_{84 M}$ & 3.95 & -0.79 & -0.44 & 2.73 \\
$J P_{120 M}$ & 3.95 & -0.56 & -0.32 & 3.08 \\
$J P_{180 M}$ & 3.95 & -0.37 & -0.21 & 3.37 \\
$J P_{240 M}$ & 3.95 & -0.28 & -0.16 & 3.52 \\
\hline Notes: as of 01/31/2000 \\
Source: Authors' calculations based on data extracted from BofA \\
ML.
\end{tabular}




\subsection{Monthly country weights}

Figure 12: Country Weights

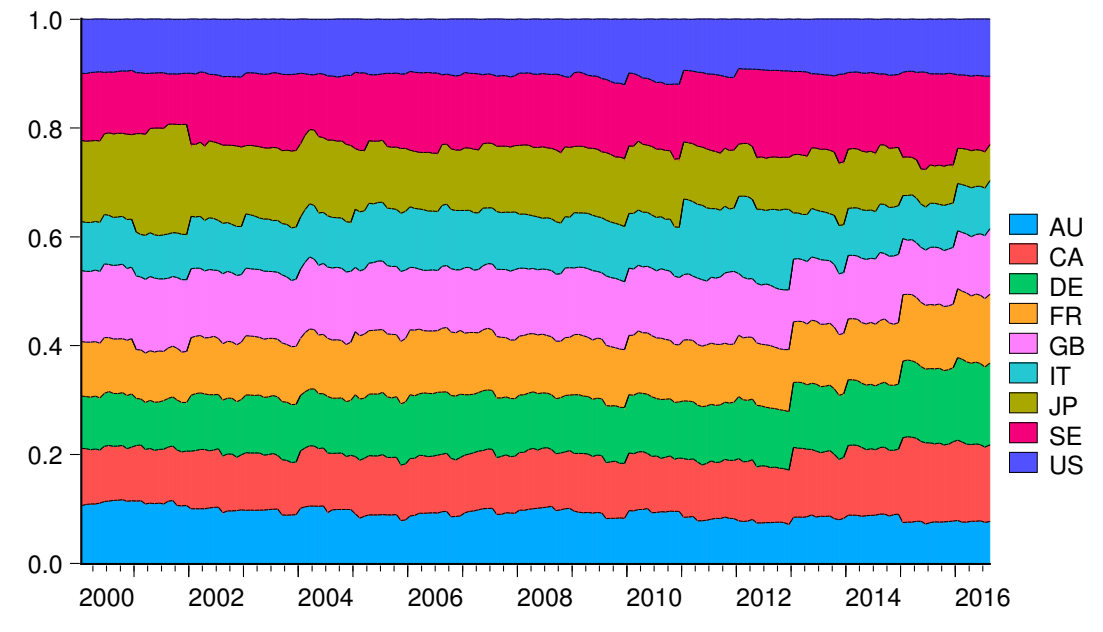

Source: Authors' calculations based on data extracted from BofA ML. 